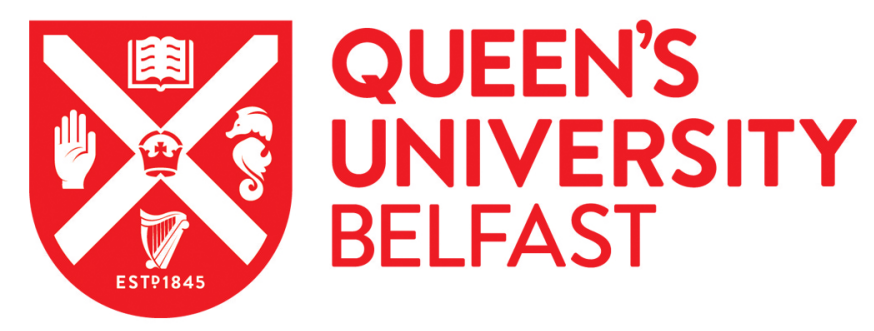

\title{
Overview of Taenia solium cysticercosis in West Africa
}

Weka, R., Kamani, J., Cogan, T., Eisler, M., \& Morgan, E. (2019). Overview of Taenia solium cysticercosis in West Africa. Acta Tropica, 190, 329-338.

\section{Published in: \\ Acta Tropica}

\section{Document Version:}

Peer reviewed version

Queen's University Belfast - Research Portal:

Link to publication record in Queen's University Belfast Research Portal

\section{Publisher rights}

Copyright 2018 Elsevier.

This manuscript is distributed under a Creative Commons Attribution-NonCommercial-NoDerivs License

(https://creativecommons.org/licenses/by-nc-nd/4.0/), which permits distribution and reproduction for non-commercial purposes, provided the author and source are cited.

\section{General rights}

Copyright for the publications made accessible via the Queen's University Belfast Research Portal is retained by the author(s) and / or other copyright owners and it is a condition of accessing these publications that users recognise and abide by the legal requirements associated with these rights.

Take down policy

The Research Portal is Queen's institutional repository that provides access to Queen's research output. Every effort has been made to ensure that content in the Research Portal does not infringe any person's rights, or applicable UK laws. If you discover content in the Research Portal that you believe breaches copyright or violates any law, please contact openaccess@qub.ac.uk. 
1 Overview of Taenia solium cysticercosis in West Africa

2 Rebecca Paul Weka ${ }^{\mathrm{a}, \mathrm{b}^{*}}$, Joshua Kamani ${ }^{\mathrm{a}}$, Tristan Cogan $^{\mathrm{b}}$, Mark Eisler ${ }^{\mathrm{b}}$, Eric R. Morgan ${ }^{\mathrm{b}, \mathrm{c}}$

3

4 aParasitology Division, National Veterinary Research Institute, PMB 01 Vom, Plateau State,

$5 \quad$ Nigeria

6 bristol Veterinary School, University of Bristol, Langford, Bristol BS40 5DU, United Kingdom

$7 \quad$ 'School of Biological Sciences, Queen's University Belfast, 97, Lisburn Road, Belfast, BT9

8 7BL, United Kingdom

$9 \quad{ }^{*}$ Corresponding author: bekkyweka@ gmail.com

10

11

12

13

14

15

16

17

18

19

20

21

22

23 


\section{Abstract}

Human and porcine cysticercosis is endemic in West Africa, where epilepsy is relatively common, but rarely reported due to fear of stigmatization. Neurocysticercosis, caused by Taenia solium, tends to affect the poor in developing countries and control is hampered by inadequate infrastructure and financial resources coupled with lack of adequate information about its significance and distribution. The risk factors for human cysticercosis are closely associated with the characteristics of smallholder or backyard pig farming systems prevalent in this region. Poverty, ignorance and lack of political will militate against successful eradication, while tools for effective diagnosis, prevention and treatment, including vaccines for pigs, are not yet available in many countries. Cysticercosis was targeted for control by The World Health Organization global plan for 2008-2015; however, measures for control are yet to be undertaken in a coordinated manner in West Africa. Diagnostic tools, including neuroimaging facilities, should be strategically situated and made accessible to rural populations in West Africa. Community education in combination with a multipronged approach consisting of vaccination of pigs using TSOL18 vaccine and treatment with oxfendazole along with mass chemotherapy of humans with praziquantel could eliminate taeniasis and should be considered in the region. Indepth and extensive epidemiological studies are required in the region in order to fully elucidate the prevalence of $T$. solium and to support more coordinated and effective control of human and porcine cysticercosis.

Keywords: Taenia solium; poverty; food safety; backyard pig farming; epilepsy; West Africa. 


\section{Introduction}

Taenia solium is a tapeworm of humans whose larval stage is normally found in pig muscle, but can also invade the human central nervous system to cause neurocysticercosis (Lightowlers, 2013; Garcia et al., 2014b), and is thus a significant cause of acquired preventable epilepsy (Winkler, 2013; WHO 2016a). Ndimubanzi et al. (2010) reported that neurocysticercosis causes $29 \%$ of acquired epilepsy in endemic countries, and epilepsy in less developed countries is responsible for mortality rates $3-6$ times higher than in developed nations (WHO, 2016a) due to inadequate infrastructure and poor access to hospitals. This zoonotic tapeworm therefore constitutes a serious, but preventable, public health problem, as well as impacting on agriculture (Ngowi et al., 2013; Braae et al., 2016a), and is considered a neglected parasite (WHO, 2016a; Johansen et al., 2016). The disease is an emergent and persistent problem in most underdeveloped areas of Sub-Saharan Africa, Asia and Latin America; except for in areas mainly populated by Muslims, who do not eat pig meat (Fleury et al., 2015).

Although T. solium has been considered an eradicable disease since 1993 by the International Task Force on Disease Eradication (ITFDE), to date none of the endemic countries has been able to eradicate this disease,.despite the advances made in the development of appropriate tools for diagnosis, treatment and prevention, neurocysticercosis still persists at disturbingly high levels in endemic areas of Africa (Johansen et al., 2016). Control of the disease in such regions is hampered by poverty, inadequate infrastructure, financial resource constraints, and unsanitary conditions (Lightowlers et al., 2015; Johansen et al., 2016). Furthermore, in Africa, ignorance surrounding the presence, magnitude and impacts of the parasite by stakeholders and political authorities have led to the disease being often unrecognized and under reported (Assana et al., 2013; WHO 2016a). This is further complicated by scarcity of information on the disease due to 
lack of overt disease manifestation in many cases in both humans and pigs (Fleury et al., 2015; Ron-Garrido et al., 2015).

In recent years, the number of studies on T. solium in Africa has increased (Gabriël et al., 2016), helping to further elucidate the epidemiology of the parasite in sub Saharan Africa (Assana et al., 2013). The purpose of this review is to summarise this new information in West Africa in the context of existing knowledge on the parasite, and to apply it to identify gaps and opportunities in research and control of this potentially devastating parasitic disease.

\section{Life cycle and disease}

Taenia solium has a two-stage life cycle. The adult tapeworm lives in the human small intestine after eating viable cysticerci ("pork measles") in raw or under-cooked pork resulting in taeniasis. The life cycle is completed when the proglottids become gravid, harboring thousands of the infective onchospheres, and are shed from the tapeworm and ingested in the faeces of infected individuals. Oncospheres (=eggs) are then dispersed and contaminate the environment.

Humans can act as accidental dead-end intermediate hosts and develop cycticercosis following ingestion of tapeworm eggs. Auto-infection can also occur when proglottids reach the stomach by reverse peristalsis, resulting in massive infection. The hatched larvae penetrate the intestinal mucosa and migrate throughout the body, forming cysticerci, which commonly lodge in skeletal muscles, eyes and subcutaneous tissues, but have a particular predilection for the central nervous system (CNS), causing neurocysticercosis (NCC) ('Gal'an-Puchades', 2016).

Pigs are the main intermediate hosts and ingest $T$. solium eggs contained in infected human feces or through ingestion of contaminated water or feed). After ingestion, the oncospheres evaginate and the hatched larvae penetrate the intestinal walls into the bloodstream and develop to 
93 metacestodes, forming cysticerci throughout the body but mostly in the striated muscles of the 94 pigs (WHO 2016a).

95

$96 \quad 2.1$ Clinical signs in pigs

97 Infected pigs are most often asymptomatic, but can rarely show neurological signs, which can 98 manifest as dullness, sluggishness, loss of consciousness, and in some cases hypersensitivity to 99 sound as well as seizures as in humans. Quivering, paralysis of the ear, ataxia, dribbling saliva, 100 circling movement, decreased production performance and social isolation have also been 101 reported (Mkupasi et al., 2014; Trevisan et al., 2016, 2017). 


\subsection{Disease in humans}

The clinical manifestations of NCC differ, varying from asymptomatic to severe (Winkler, 2013; Trevisan et al., 2016). Seizures are the most common presentation of NCC in humans (Carpio and Romo, 2014) occurring in about $60-90 \%$ of symptomatic infections (Rodrigues et al., 2012; Carpio et al., 2013), although incidence varies in different regions according to socioeconomic and cultural practices (Del Brutto, 2013b; Winkler, 2013). Headache (Carabin et al., 2011;Johansen et al., 2016), focal neurological signs (Fleury et al., 2011; Flisser, 2013) and generalized weakness associated with muscle pseudohypertrophy (Fleury et al., 2015) are also common presentations noticed.

It has been estimated that between 2.6 and 8.3 million individuals are affected globally by symptomatic and asymptomatic NCC, and that 0.76-2.46 million of the NCC-related epileptic individuals and 0.95-3.08 million of the asymptomatic NCC individuals are in sub-Saharan Africa (Winkler, 2013), resulting in 2-5 million lost disability-adjusted life years (WHO, 2015b).

\section{Diagnosis}

\subsection{Diagnosis of porcine cysticercosis}

Diagnosis of porcine cysticercosis is essential for control, to prevent taeniasis in humans and further onward infections in pigs as well as NCC in humans (Gilman et al., 2012).

\subsubsection{Tongue and carcass inspection}

The simplest and most common diagnostic methods for porcine cysticercosis are visual inspection of the surface of the tongue, which has a sensitivity ranging from 16-70\% (Phiri et al., 2006), and carcass inspection (Lightowlers et al., 2015). Most epidemiological studies on 
porcince cysticercosis in West Africa have used tongue or carcass inspection (Onah and

126 Cheinjina 1995; Gweba et al., 2010; Goussanou et al., 2014; Edia-Asuke et al., 2014; Attawalna

127 et al., 2015; Idiaka et al., 2017).

128 Gap:Tongue and carcass inspection are commonly applied to check meat safety in West Africa,

129 however can inadvertently lead to the entrance of a large amount of pork infected with 130 cysticercosis into the human food chain at a reduced price, due to the low sensitivity of the 131 technique (Goussanou et al., 2014). Exemplified by studies of Onah and Cheinjina (1995) who 132 observed $5.5 \%(72 / 1300)$ of pigs were infected with cysticercosis infection based on tongue 133 inspection while carcass inspection also showed that all 72 were infected, including the $8.5 \%$ 134 (104) that were negative by tongue inspection. Futhemore Gweba et al.(2010) also observed a 135 prevalence of $5.85 \%(\mathrm{n}=205)$ and $14.40 \%(\mathrm{n}=118)$ by lingual palpation and postmortem 136 examination. The infected meat could be a source of infection to the public if mechanisms are 137 not in place for the proper disposal of infected meat (Gonzalez et al., 1990). Hence studies by 138 Lightowlers et al. (2015) indicate that slicing the tongue, masseter muscle and heart is highly 139 specific and detects natural infection in pigs with $80 \%$ sensitivity at a low cost, especially 140 because these are convenient anatomical sites which will not affect the carcass value hence such 141 technique should be practiced in West Africa.

\subsubsection{Serology in pigs}

144 Serological tests for the detection of specific antibodies or specific antigens use enzyme-linked 145 immunosorbent assay (ELISA) and electro-immuno transfer blot (EITB) (Lightowlers et al., 146 2016). Most of the few serological studies of pigs in West Africa have used B158/B160 Ag- 
ELISA (Secka et al., 2010a; Ganaba et al., 2011) and studies of Weka et al. (2009) used IgG antibody ELISA.

149 Gap; Lack of serological diagnostic kits in West Africa especially due to cost is a serious obstacle to providing detailed epidemiological data hence, availability of serological kits in the region will help in diagnosis of porcine cysticercosis. However, detection of antibodies does not necessarily imply active infection as serologically positive pigs may not have cysticerci at necropsy (Jayashi et al., 2012; Devleesschauwer et al 2013; Lightowlers et al., 2016). Moreover,

154 false positive or transient positive reactions might arise from exposure to $T$. solium eggs that did not develop to cysticerci to be detected at carcass inspection (Lightowlers et al., 2016).

156 Generally, antigen detection methods are by far superior to antibody detection techniques since

157 they indicate the presence of viable cysts. Although at population level, results can nevertheless 158 give a useful indication of infected areas where the life cycle of the parasite is ongoing (Thomas,

159 2015). Thus serological test interpretation in individual animals is limited by their sensitivity and 160 specificity (Lightowlers et al., 2016) and should be confirmed by necropsy where possible 161 although purchasing pigs for necropsy is equally expensive.

\subsection{Diagnosis in humans}

\subsubsection{Serology in humans}

164 Serological studies for diagnosis of human cysticercosis has been carried out in West Africa, 165 including the use of Ag-ELISA (Nitiéma et al., 2012; Carabin et al., 2015), Ab- ELISA (Edia166 Asuke et al. 2015; Weka et al. 2013) and EITB (Secka et al., 2010a; 2011). The EITB assay

167 developed by Tsang et al. (1989), though about 20 times more expensive than ELISA is highly 168 specific (near-100\%) and sensitive (70-90\%). Antibody seropositive individuals, however, might 169 have been exposed to the parasite or naturally cured and do not necessarily have an established 
infection; hence, results should be interpreted in line with the clinical presentation (Gilman et al.,

171 2012). However, antigen-ELISA is highly sensitive, cost effective and technicaly simpler to

172 implement in resource limited settings and will be an invaluable tool for hospital diagnosis, 173 particularly in the absence of imaging facilities.

174 Gap; ELISA kits for antibody detection in human cysticercosis are commercially available 175 (Rodriguez et al., 2012) but they are reported to have low sensitivity and frequent cross-reactions 176 (Garcia et al., 2018) hence, the results should be interpreted with caution. Therefore, research 177 laboratories in West Africa should give priority to the development of ELISA using local 178 cysticercal antigens to enhance diagnosis and facilitate the much needed epidemiologic studies in 179 most of Africa.and the financial burden of running the EITB precludes its routine use.

180

\subsubsection{Diagnosis of NCC}

182 Diagnosis of NCC is mainly pursued by neuroimaging techniques, including computerised tomography (CT) and magnetic resonance imaging (MRI), (Gilman et al., 2012; Fleury at el.,

184 2013) which detects the presence of parasitic lesions/ calcified cysts and extraparanchymal 185 lesions, and can give a sensitive and accurate diagnosis of NCC (Nash and Garcia, 2011; Gilman 186 et al., 2012). Only few surveys in West Africa have used imaging techniques (Secka et al., 187 2010b; Milogo et al., 2012).

188 Gaps; Neuroimaging facilities are expensive and not easily available for studies in West Africa 189 and hence such diagnostic facilities should be made available in research institutes or 190 government hospitals in the region where it can easily be assessed by researchers. 
The presence of adult $T$. solium tapeworms may be detected by stool microscopy, and observation of Taenia sp. tapeworm eggs or sometimes adult tapeworm segements (Lightowlers et al., 2016). Coproscopy has been used in human surveys in West Africa (Gweba et al., 2010; Secka et al., 2011).

197 Gap; This test has poor sensitivity (Lightowlers et al., 2016), and misses 60-70\% of cases (Mayta et al., 2000). Moreover, it is not possible to differentiate between T. solium and T. saginata eggs, which are morphologically similar (Garcia et al., 2003; Lightowlers et al., 2016). Therefore results of stool microscopy should be interpreted with caution and more sensitive diagnostic 201 techniques should be made available in the region.

202 Coproantigen detection is more sensitive than stool microcopy as reported by Allan et al. (1996) 203 where the detection rate was $5 \%$ and $1 \%$ for the former and the latter resepectively. A species204 specific coproantigen ELISA developed by Guezala et al. (2009) detects Taenia-specific molecules in faecal samples. Although the test has a reported sensitivity of $96.4 \%$ and specificity of $100 \%$ for $T$. solium carriers, it is important not to base a diagnosis solely on this test. Moreover, the test is no longer commercially available. Studies of Edia-Asuke et al. (2014) in West Africa used coproantigen ELISA which involved the use of polyclonal antibodies to identify copro antigens in feaces, hence such kits if made available to researchers in West Africa

210 will give a better picture of the prevalence of taeniais in the region.

211 Other diagnostic methods include the PCR and restriction enzyme analysis (REA) test developed 212 by (Mayta et al., 2000), which has several advantages, it avoids the use of scarce, expensive and 213 radioactive reagents and specialized equipment and uses only two steps to differentiate the 214 tapeworms. A multiplex PCR for differential diagnosis of T. solium, T. saginata and T. asiatica 215 was also developed by Yamasaki et al. (2004). More recently, loop-mediated isothermal 
amplification (LAMP) for T. solium DNA which does not need complicated equipment was developed (Nkouawa et al. 2010). This method could differentially diagnose T. saginata, T. solium and T. asiatica in 37 of $43(86 \%)$ parasitologically diagnosed cases of taeniasis (Nkouawa et al., 2010; 2012).

220 Gaps; These tests, however, are technically demanding and most of them have not been used in studies carried out in West Africa, however its availability and use by researchers in the region will make it possible for elaborate estimate figures of taeniasis to be generated which will invariably reduce under reporting/under estimation of results in the region .

\section{Current status of Taenia solium infections in West Africa}

\subsection{Human taeniasis and NCC}

Taenia solium cysticercosis is present in most West African countries since favorable conditions for parasite transmission in both humans and pigs occur widely in the region, such as defecation in the open field, illicit slaughtering of pigs and unqualified meat inspectors (Gweba et al., 2010; Weka et al., 2013; Carabin et al., 2015). The prevalence of cysticercosis / NCC and taeniasis in humans is shown below (Tables 1and 2). Stubbornly persistent high prevalence of neurocysticercosis has been reported in countries such as Burkina Faso and Senegal (Fleury et al., 2013). In Burkina Faso, NCC is common, with $12-17 \%$ of people suffering from epilepsy

234 testing positive for T. solium (Millogo et al., 2012; Nitiéma et al., 2012). In Nigeria, a study by 235 Edia-Asuke, et al. (2015) showed an association between epilepsy and cysticercosis, such that 236 individuals with epilepsy were twice as likely to test seropositive compared to non-epileptics. 237 Cases of taeniasis have also been widely reported in the region (Table 2). There are important 
238 gaps in knowledge of prevalence, for example no recent published data on human cysticercosis 239 in Guinea-Bissau or Liberia. 


\begin{tabular}{|c|c|c|c|c|c|}
\hline Country & Prevalence $(\%)$ & Diagnosis & Test method & Subjects & References \\
\hline \multirow[t]{4}{*}{ Burkina Faso } & $\begin{array}{ll}0 & - \\
(120 / 3609) & 11.5\end{array}$ & B158/B60 Ag-ELISA & NS & Villagers & Carabin et al., 2015 \\
\hline & $17(10 / 60)$ & B158/B60 Ag-ELISA & NS & PWE & Milogo et al., 2012 \\
\hline & $29.4(20 / 68)$ & CT-Scan & Specific & PWE & Milogo et al., 2012 \\
\hline & $12.8(5 / 39)$ & B158/B60 Ag-ELISA & NS & PWE & Nitiéma et al., 2012 \\
\hline \multirow[t]{2}{*}{ Nigeria } & $9.6(12 / 125)$ & ELISA (IgG) & NS & Villagers & Weka et al., 2013 \\
\hline & $14.3(43 / 300)$ & ELISA (IgG) & NS & Butchers & $\begin{array}{l}\text { Edia-Asuke et al., } \\
2015\end{array}$ \\
\hline \multirow[t]{3}{*}{ Senegal } & $7.7(31 / 403)$ & B158/B60 Ag-ELISA & NS & Villagers & Secka et al., 2011 \\
\hline & $7.7(31 / 403)$ & EITB & Specific & Villagers & Secka et al., 2011 \\
\hline & $23.3(10 / 43)$ & CT-scan & Specific & Seropositive & Secka et al., 2011 \\
\hline Gambia & 0 & EITB, CT-Scan & Specific & 630 PWE and controls & Secka et al., 2010b \\
\hline
\end{tabular}

243 Table 1. Prevalence of cysticercosis in both people with epilepsy (PWE) and general villagers in West Africa by serology and imaging

244 methods. Prevalence is given in percent, followed by positive cases / sample size in brackets). Ag-ELISA = Antigen ELISA=Enzyme

245 linked immunosorbent assay; CT = Computed Tomography. NS = method is not specific for T. solium. 


\begin{tabular}{lllll}
\hline Country & $\begin{array}{l}\text { Prevalence } \% \\
(\mathbf{N})\end{array}$ & Target group & Test & References \\
\hline Ghana & $0(1080)$ & Schoolchildren & Stool microscopy & Nkrumah and Nguah, 2011 \\
& $1.1(3 / 292)$ & Villagers & Stool microscopy (Kato-Katz) & Humphries et al., 2011 \\
& $13(65 / 494)$ & Villagers & Stool microscopy (Kato-Katz) & Bimi et al., 2012 \\
Nigeria & $30(3 / 10)$ & Adult butchers & Copro-Ag-ELISA (T. solium) & Edia-Asuke et al., 2014 \\
& $8(4 / 50)$ & Villagers & Stool microscopy (Taenia spp.) & Gweba et al., 2010 \\
Gambia & $4.7(2 / 43)$ & Villagers & Stool microscopy (Taenia spp.) & Secka et al., 2011 \\
\hline
\end{tabular}

252

253 Table 2. Prevalence of taeniasis in human faecal samples in West Africa. Prevalence is given in percent, followed by positive cases /

254 sample size in brackets.

255 
257 Reports indicate that the West African region has the largest pig population on the African 258 continent (Ngowi et al., 2013), having increased by $23 \%$ between 1985 and 2005 (FAO, 2012). 259 Available data on the current status of porcine cysticercosis in West Africa, determined by 260 serological or carcass inspection, is presented in Table 3.

261 Gaps;Although there are no recent data on porcine cysticercosis in several countries in West 262 Africa, e.g. Togo (Dumas et al., 1989, 1990), T. solium is highly prevalent in the pig raising parts 263 of the wider region, including in Senegal, Gambia (Secka et al., 2010a, b; Secka et al., 2011) and 264 Nigeria (Gweba et al., 2010). There is a need for more epidemiological studies using suitable 265 diagnostic technologies and neuroimaging to produce a more comprehensive picture.

\begin{tabular}{|c|c|c|c|c|}
\hline Country & $\begin{array}{l}\text { Prevalence \% } \\
\text { (sample size) }\end{array}$ & Diagnostic method & $\begin{array}{l}\text { Test } \\
\text { method }\end{array}$ & Reference \\
\hline Burkina Faso & $32.5-48.2(336)$ & B158/B60 Ag-ELISA & NS & Ganaba et al., 2011 \\
\hline Gambia & $4.8-13.2(1705)$ & B158/B60 Ag-ELISA & NS & Secka et al., 2010a \\
\hline Ghana & $2.3(4121)$ & Carcass inspection & Specific & Atawalna et al., 2015 \\
\hline Nigeria & $\begin{array}{l}18.8(117) \\
11.7(60) \\
2.4(379) \\
5.9(205)\end{array}$ & $\begin{array}{l}\text { Carcass inspection } \\
\text { Carcass inspection } \\
\text { Carcass inspection } \\
\text { Tongue inspection }\end{array}$ & $\begin{array}{l}\text { Specific } \\
\text { Specific } \\
\text { Specific } \\
\text { Specific }\end{array}$ & $\begin{array}{l}\text { Bimi et al., } 2012 \\
\text { Permin et al., } 1999 \\
\text { Idiaka et al., } 2017 \\
\text { Gweba et al., } 2010\end{array}$ \\
\hline & $\begin{array}{l}14.4(118) \\
20(2358)\end{array}$ & $\begin{array}{l}\text { Carcass inspection } \\
\text { Carcass inspection }\end{array}$ & $\begin{array}{l}\text { Specific } \\
\text { Specific }\end{array}$ & $\begin{array}{l}\text { Gweba et al., } 2010 \\
\text { Onah and Cheinjina } 1995\end{array}$ \\
\hline & $\begin{array}{l}9.3(43) \\
46(115)\end{array}$ & $\begin{array}{l}\text { Carcass inspection } \\
\text { IgG antibodies }\end{array}$ & $\begin{array}{l}\text { Specific } \\
\text { NS }\end{array}$ & $\begin{array}{l}\text { Edia-Asuke et al., } 2014 \\
\text { Weka and Ikeh, } 2009\end{array}$ \\
\hline Senegal & $6.4-13(1334)$ & B158/B60 Ag-ELISA & NS & Secka et al., 2010a \\
\hline
\end{tabular}

Table 3. Prevalence of porcine cysticercosis in pigs in West Africa. Prevalence is given in percent, followed by sample size in brackets. AgELISA $=$ Antigen Enzyme linked immunosorbent assay; IgG = Immunoglobulin G. NS = not specific for T. solium.

\subsection{Economic burden of human disease}


Neurocysticercosis resulting in epilepsy is a significant health problem in many developing countries (Carabin et al., 2015; Johansen et al., 2016), leading to disproportionate economic suffering in underprivileged populations (Ferrer and Garate 2014; Gabriël et al., 2016; WHO 2016a). Reports from most parts of West Africa show that epileptics suffer discrimination, stigmatization, joblessness and disability (Nitiéma et al., 2012; Komolafe et al., 2012; Osakwe et al., 2014). Negative attitudes and behaviours toward epileptics by the general population are due to ignorance and mistaken perceptions. In Nigeria some people believe that epilepsy is caused by witchcraft or evil spirits or that it is directly contagious, and sufferers therefore often seek treatment from herbalists, faith healers or witch doctors (Osakwe et al., 2014). Hence detailed epidemiological surveys in order to generate data on communities' perception of epilepsy especially in relation to prevalence of epilepsy in NCC patients should be carried out in the region. Such a study will be used to serve as a guide in community treatment and social intervention packages (Osakwe et al., 2014) to help change the negative perceptions that the populace have towards the epileptics.

\subsection{Economic impacts of porcine cysticercosis}

Porcine cysticercosis significantly impacts pig production in sub-Saharan Africa (Gabriël et al., 2016; Trevisan et al., 2017), resulting in nutritional and financial losses for smallholder farmers (Johansen et al., 2016; Ngowi et al., 2013). Previous studies by Zoli et al. (2003) indicate that annual losses resulting from porcine cysticercosis in 10 West and Central African countries is estimated at 25 million Euro, no recent region-wide economic information or reports are however, available for West Africa except for studies of Atawalna et al.(2015) in Ghana where 
the authors gave an estimate of 104,528.11 Ghana Cedis was lost directly annually due to porcine cysticercosis

\section{Risk factors for transmission in West Africa}

The human populations considered to be at the highest risk of infection are those who earn their livelihood wholly or partially through livestock rearing, including pigs, and have limited access to good sanitation (Carabin et al., 2015; WHO, 2016a). Here we discuss risk factors especially relevant to transmission of T. solium in West Africa.

\subsection{Changing societal context}

305 Increasing demand for meat and urbanization of populations in Africa are driving emerging

306 livestock systems, including backyard pig rearing without sanitary precautions. The scenario is

307 further complicated due to lack of potable water and poor sanitary conditions, which were 308 reported as risk factors for taeniasis in a study conducted in Nigeria, in which Taenia spp. eggs 309 were detected in soil and water (Gweba et al., 2010). Unhygienic practices like dumping faecal 310 matter in the surroundings, eating unwashed fruit and vegetables, and drinking unsafe (i.e. not 311 boiled or otherwise treated) water contaminated with Taenia spp. eggs, are important risk factors 312 for infection with T. solium in Burkina Faso (Carabin et al., 2015). Hence provision of portable 313 drinking water should be made to communities which will prevent not only taeniasis but includes 314 other diseases and will also improve sanitation and hygiene in the region. 
317 A strong link between various husbandry and sanitary practices and risk of infection in pigs and 318 humans in West Africa has been established. The traditional system of pig management where 319 most of the pigs are confined or tethered at night, and usually allowed to roam freely and 320 scavenge during the day, is a common practice in West Africa and is likely to influence the 321 prevalence of porcine or human cysticercosis, as observed in Burkina Faso (Ganaba et al., 2011). 322 In that study, porcine cysticercosis was associated with rearing practices, especially in the rainy 323 season, in which pigs left to roam briefly during the rainy season were more likely to be 324 seropositive than those kept confined in pens. Seropositivity for human cysticercosis in a village 325 population in Senegal was also linked to free roaming pigs having access to human defecation 326 sites (Secka et al., 2011). In Nigeria, Gweba et al. (2010) observed that pigs had access to 327 farmlands that were used as defecation sites by farmers. Weka et al. (2013), also in Nigeria, 328 showed that extensively raised pigs had significantly higher seroprevalence of cysticercosis 329 compared to those that were raised under more intensive management systems. The traditional 330 system of pig management is therefore a risk factor for transmission of the disease; hence 331 farmers should adviced to confine their pigs if possible.

\subsection{Human dietary behavior}

334 Changing human behavior is a crucial component of solving the problem of cysticercosis in West 335 Africa. For example, there is a lack of coordinated meat inspection and illegal slaughtering is 336 commonly practised, resulting in infected carcasses being marketed and consumed even when 337 under cooked, especially during festivities exposing humans in the area at risk of taeniasis and 338 cysticercosis. In some instances, there are no abattoirs or slaughters slabs in the locality for meat 339 inspection to be carried out, and if present are often unregistered. This was a common scenario 
observed in studies conducted in Nigeria, Senegal and Gambia (Gweba et al., 2010; Secka et al.,

341 2010a, Edia-Asuke et al., 2014).

\subsection{Butcher and inspector practices in abattoirs}

Meat inspection regulations vary from one country to another (Dorny et al., 2005; Goussanou et al., 2014). Usually, butchers carry out basic visual inspection, sometimes supplemented by

348 incisions of parasite preference sites, as for example in Benin (Goussanou et al., 2014). Butchers 349 may allow only one incision to avoid disfigurement of meat as reported in Nigeria (Gweba et al.,2010); a lack of multiple incisions renders the technique of low value, as cysts may be missed, thereby reducing sensitivity and observed prevalence (Goussanou et al., 2014). Some inspectors in Benin also allow butchers to sell meat from carcasses with immature cysts, with the recommendation to cook thoroughly before consumption (Goussanou et al., 2014). Confounding the issue also are the middle men who exert pressure to get the meat away from the slaughter slabs and quickly to the market place, thereby preventing thorough meat inspection as observed in Nigeria (Gweba et al., 2010). Although existing legislation in many African countries requires that cysticercotic pig carcasses be condemned at meat inspection, this does not usually occur. Rather, infected pig carcasses are sold to consumers at reduced prices in Nigeria (Weka, personal observation) as commonly observed in other African countries (Ngowi et al., 2013) which

360 promotes spread of infection and further pushes the burden of disease onto the poor, who cannot 361 pay the premium for safe meat,therefore proper meat inspection should be carried out to curb 362 spread of the disease. 


\subsection{Pork preparation and consumption}

365 There are indications that pork consumption is increasing in sub-Saharan Africa, while 366 preparation methods in the region often do not effectively kill the cysticerci (Assana et al., 367 2013). Heat resulting from boiling and frying the pork passes through the meat to a greater extent 368 and is more likely to kill the cysts, compared to heat from roasting or barbecue grilling, as 369 reported in Nigeria (Edia-Asuke, et al., 2015).Studies conducted in Ghana, Nigeria and Burkina 370 Faso indicated that those who ate pork with cysticerci and those who ate lightly cooked pork 371 soups in the markets had higher probabilities of taeniasis (Bimi et al., 2012; Weka et al., 2013;

372 Carabin et al., 2015). In Benin it is frequently eaten in form of a meat product named "kpete" 373 (kind of pudding) which are not always sufficiently heated to kill all cysticerci (Goussanou 374 (2010). Consumers should be encouraged to cook meat thoroughly before consumption to halt spread of infection.

\subsection{Hygiene practices}

Open defecation, poor personal hygiene and low environmental sanitation including improper faecal disposal are common practices in West Africa and are habits that promote the spread of $T$. solium (Gweba et al., 2010; Secka et al., 2011; Weka et al., 2013). It has been reported that persons who do not use toilet facilities or did not wash their hands after defecation were 8.3 and

3825.5 times respectively to test seropositive compared to those who used water closet toilet

383 facilities and regularly washed their hands after defecation (Weka et al., 2013). A similar report 384 had been made in Burkina Faso (Ganaba et al., 2011; Carabin et al., 2015).

$385 \quad 5.7$ Lack of knowledge 
In endemic areas, poverty, ignorance and superstitious beliefs about $T$. solium are associated with increased risk of disease transmission and stakeholders in endemic areas may know about tapeworm infections in humans but could not relate them to porcine cysticercosis and NCC (Thys et al., 2015). In a study in Nigeria, $80 \%$ of the butchers had poor knowledge of T. solium cysticercosis and its public health significance (Edia-Asuke et al., 2014), a likely explaination for 391 the persistently high-risk practices as described above.

\section{Treatment of Taenia solium infections}

\subsection{Treatment of neurocysticercosis/Taeniasis}

There is no universally accepted gold standard for the treatment of NCC but several suggestions 396 have been made (Winkler, 2013; Garcia et al., 2014b). Pharmacological therapy succeeds in 397 eliminating active cysts in only one third of patients (Carpio and Romo, 2014).

398 Albendazole is one of the cysticidal drugs of choice because of its ability to penetrate the central nervous system (Garcia et al., 2014a). Another drug of choice is praziquantel, which is widely accessible in sub-Saharan Africa and is effective against cestodes and schistosomes (Evans et al.,

401 2013; Braae et al., 2015c). Mass praziquantel treatment has been used widely in schistosomiasis control in Africa. There are no data available yet on widespread treatment for T. solium 403 infections in humans in West Africa; however, several countries in the region have carried out 404 MDA against schistosomiasis using praziquantel (Garba et al., 2009; Evans et al., 2011; Leslie et 405 al., 2012). The drug is very effective in the treatment of taeniasis at a single oral dose rate of 5$40610 \mathrm{mg} / \mathrm{kg}$ and therefore can be used to treat against both parasites (Braae et al., 2015a). 407 Unfortunately, the recommended dose for the treatment of schistosomiasis $(40 \mathrm{mg} / / \mathrm{Kg})$; (WHO 408 2002) stimulates seizures in people with NCC (Johansen et al., 2016). It has been observed that 
integration with schistosomiasis control programmes is a good way forward for control of $T$. solium, and will also control other co-endemic infections (Braae et al., 2015a).

411 The safety of praziquantel for mass drug administration (MDA) in West Africa is yet to be 412 evaluated in the light of high prevalence of NCC. Niclosamide is also another drug of choice for 413 eliminating adult tapeworm burdens (Gilman et al., 2012), but must be used with caution 414 especially in people with NCC. Adult worms eliminated by the patients constitute a serious 415 hazard to the populace and the environment and must be safely disposed off. It may also be 416 necessary to treat any newcomers to the region that might be carriers, and those returning from 417 regions where transmission of T. solium is still ongoing (Geerts, 2016).

\subsection{Treatment of cysticercosis in pigs}

420 The benzimidazole drug, oxfendazole is very effective against muscle cysts and gastrointestinal 421 helminths at a single dose of $30 \mathrm{mg} / \mathrm{kg}$ body weight, but has limited effect on brain cysts (Pondja et al., 2012; Mkupasi et al., 2013a, b). Additional benefit of the use of oxfendazole in pigs is that it increases the growth rate and general condition by eliminating other gastro intestinal nematodes.

The use of oxfendazole alone is often unable to control T. solium, as shown in a high endemic area in Mozambique (Pondja et al., 2012). This is because some animals are likely to get reinfected following the last treatment and prior to slaughter. The role of drug treatment in the

428 development of immunity againt reinfection in endemic areas is uncertain. Further, in heavily 429 infected pigs, inflammatory reactions arise in reaction to the anthelmintic-mediated death of 430 cysticerci in the muscles (Assana et al., 2010), and can make the meat unfit for marketing and 431 subsequent consumption (Lightowlers, 2010). The prolonged treatment time and withdrawal 
period following the use of oxfendazole before the animals are sold for consumption constitutes

433 a major constraint to the effective control of $T$. solium in most rural communities where the pigs

434 are the main source of income for the farmers. In Morocco north Africa,oxfendazole is marked 435 under the trademark Paranthic ${ }^{\odot}$ at a price of 0.5 US dollars per $30 \mathrm{~kg}$ pig, which is motivating to 436 small-scale pig farmers (Lightowlers, 2013; Donadeu and Lightowlers, 2014; Geerts, 2016), 437 however, data on the availability, acceptability and affordability of the drug in West Africa is 438 lacking.

\section{Control}

441 Taenia solium cysticercosis is still endemic in West Africa despite the availability of tools to 442 disrupt the life cycle (Braae et al., 2015b). The World Health Organization (WHO) included T. 443 solium cysticercosis as one of the major neglected tropical diseases (NTDs), and has adopted a 444 resolution for intensified control efforts (WHO, 2010; Braae et al., 2016b). The resolution recommended a scaled-up control and eradication strategy in selected countries to last from 2016 to 2020 with the aim to control and eradicate the disease by 2020 . However; no large scale taeniasis control programme, has yet been implemented in sub-Saharan Africa (WHO, 2015c). Below, we consider the approaches available and how they have been and might be more 449 effectively applied in West Africa.

\subsection{Use of latrines to reduce open defecation}

453 The availability and use of toilets or latrines will decrease the spread of Taenia spp. eggs and 454 other soil-transmitted helminths (STH) in the environment (Bethony et al., 2006; Pruss-Ustun et 
al., 2014). Moreso, emphasis should not be on the provision and use of latrines or access to sufficient clean water only but also on the proper management of such infrastructures by the population (Gabriël et al., 2016). The assessments of community-led total sanitation (CLTS) as an intervention measure for the control of porcine cysticercosis has not yet been fully evaluated as part of T. solium control in West Africa, hence the communities should be encouraged to stop open defecation and practice CLTS. However, studies in The Gambia and Senegal reported that $93 \%$ of the residents had toilets and only $5 \%$ used open defecation and that the $5 \%$ were likely to be responsible for considerable environmental contamination with Taenia spp. eggs (Secka et al., 2010a). A study from Nigeria showed that although $93 \%$ of households in the study location had toilets, majority of them still defecate on farmlands thereby contaminating the environment with Taenia spp. eggs (Gweba et al., 2010).

\subsection{Personal and household hygiene}

469 Individual and community hygiene should also be emphasized and encouraged in order to 470 decrease the risk of NCC, including the availability of sufficient clean water which is crucial to 471 allow improved hygiene (Gabriël et al., 2016). A study in Nigeria showed higher risk (31.7 472 times) of exposure to taeniasis among respondents who do not wash their hands after each toilet 473 use compared to those who wash their hand with soap and water (Weka et al., 2013). Enough 474 water for washing of fresh foods- fruits and vegetables is also necessary to reduce the spread of 475 Taenia spp. eggs as reported from studies carried out in Bukina faso (Carabin et al., 2015) .

\subsection{Confinement of pigs}


Traditional systems of pig management is commonly observed in West Africa and is likely to influence the prevalence of porcine or human cysticercosis (Ganaba et al., 2011; Secka et al., 2011; Weka et al., 2013). The ability of farmers to provide pig housing is hindered by poverty, since the farmer is also expected to provide feed to the pigs under the confined systems of management (Assana et al., 2013). This runs in opposition to the motives of the smallholder farmer, to keep pigs as a source of income without the need to invest in feed (Gilman et al., 2012) which renders pig confinement an unworkable approach to T. solium control in the short term and changes in pig management systems should be considered a long term strategy (Thomas, 2015). However pig farmers should also be informed that apart from the advantage of a decrease in porcine cysticercosis, confined pigs also have a reduced risk of acquiring African Swine Fever (Geerts 2016), and decreased burden of other parasites (Gabriël et al., 2016).

Gap;Changes in pig rearing system are likely to be driven by economic more than sanitary considerations, but research on the constraints and consequences of adopting different systems, and related trade-offs with time and funds available for other activities, resilience to internal and external disruptions, and animal welfare, remain un-studied in West Africa.

\subsection{Meat and lingual inspection}

Both meat and tongue inspection are carried out in West Africa in locations where slaughter slabs and abattoirs for pigs exist (Onah and Chiejina, 1995; Coulibaly and Yameogo, 2000; Gweba et al., 2010; Secka et al., 2010b; Edia Asuke et al., 2014; Goussanou et al., 2014; Idiaka et al., 2017). These techniques are relatively cheap, rapid and easy to conduct (Goussanou et al., 2013), their sensitivity, however, is low therefore, lightly infected pig carcasses undetected by 
this method are likely to go into the food chain and serve as a source of infection in the community as reported in Benin (Goussanou et al., 2014). Furthermore, farmers and traders in Benin frequently carry out tongue examinations to detect cysts prior to marketing in order to avoid condemnation, and then often use the infected carcase for their own consumption or sell it illegally (Goussanou et al., 2013).

Gap; The lack of comprehensive and satisfactory meat inspection in West Africa is a significant risk factor for the transmission of cysticercosis to humans. In Nigeria, the situation is further complicated by the lackadaisical attitude of inspectors, apathy from the farmers, insincerity of

510 policy makers, and consumers who prefer to buy infected carcasses at a cheap price without 511 regard for the health implications (Weka, personal observation). Strict meat inspection and condemnation of infected carcases runs the risk of exacerbating the divide between safe but expensive meat and cheaper but riskier 'unofficial' meat, further pushing the burden of disease onto the poor. Research is needed that encompasses the economic, social and behavioural context of meat safety as well as biological and veterinary processes.

\subsection{Meat processing}

518 Proper meat processing at household and community level is an important defence against NCC

519 (Ertel et al., 2015). Freezing for 10 days at $-10{ }^{\circ} \mathrm{C}$, gamma-radiation, cooking and salt pickling 520 of pork meat infected with T. solium all decrease cyst viability (OIE, 2015; Geerts 2016).

521 Gap; Implementation in rural areas is often difficult due to cost and unavailability of equipment 522 (Geerts, 2016). Lack of freezers, unreliable power supply, and impatience of consumers militate 523 against prolonged freezing of meat as a control measure in West Africa. Although meat is 
normally well cooked in endemic areas (Geerts, 2016), as temperature of $80{ }^{\circ} \mathrm{C}$ will also kill $\mathrm{T}$. solium cysticerci in infected meat (OIE, 2015), studies in including West Africa indicated that the pork meat it is frequently eaten in forms which are not always sufficiently heated to kill all cysticerci (Goussanou 2010; Edia-Asuke, et al., 2015).

\subsection{Anthelmintic treatment of pigs and humans}

Treatment of cysticercosis in pigs and taeniasis in people can be usefully applied as MDA at population level using a single dose of $5 \mathrm{mg} / \mathrm{kg}$ praziquantel or nitazoxanide ( $2 \mathrm{~g}$ ) as an effective control measure. A $56 \%$ decrease of prevalence of taeniasis after 42 months was reported in Mexico while 1-3.5 \% decrease in cases of taeniasis and a 7-55\% decrease in porcine cysticercosis in two villages in Guatemala 10 months after evaluation was reported (Allan et al., 1997). Gap; Studies using combined treatment of pigs and humans in West Africa have not yet been reported.

\subsection{Vaccination of pigs}

Vaccination is a recently available intervention for the control and elimination of $T$. solium (Lightowlers, 2013; Gabriël et al., 2016), and has conferred high levels of protection in both experimental and field trials (WHO, 2015a, 2016a). Three candidate vaccines currently exist, based on: a crude antigen developed by Molinari et al. (1993); a recombinant oncosphere antigen-based TSOL16 or TSOL18 vaccine by Lightowlers et al.(2010); and a peptide-based S3PVac developed by Huerta et al. (2001). The most effective vaccine produced to date is the recombinant protein TSOL18, which achieved $99 \cdot 5-100 \%$ protection of vaccinated pigs in a field trial in Cameroon when combined with a single oxfendazole treatment (Assana et al., 
2010). In the study, the first vaccine dose was given at 2-3 months of age, and a second vaccine 548 dose given with oxfendazole 4 weeks later. A third vaccine dose was given 3 months later. The combination of TSOL18 vaccination and oxfendazole in pigs has the potential to control transmission in endemic areas and indirectly decrease new cases of NCC (Assana et al., 2010).

551 The oxfendazole eliminates any T. solium infection that is already present in the vaccinated pigs, 552 prior to the animals being fully vaccinated and protected (Lightowlers, 2013). The regimen 553 allows adequate time to pass after chemotherapy for any lesions in the pork arising from killed 554 and necrotic cysticerci to be resolved prior to the animals being slaughtered. During this period, 555 all animals (previously infected or otherwise) are protected against new $T$. solium infection by 556 the vaccine. A smilar result was obtained in a field trial conducted in Peru (Jayashi et al., 2012).

557 The effectiveness of $T$. solium taeniasis-cysticercosis elimination by combined vaccination 558 (TSOL18) plus treatment of pigs with oxfendazole, combined with mass or targeted treatment of 559 human tapeworm carriers (Geerts, 2016) led to marked reduction in T. solium transmission in the 560 study populations (Garcia et al., 2010; Gilman et al., 2012). Challenges remain, however, in 561 achieving optimal protection of traditionally managed pigs under field conditions (Lightowlers, 562 2013; Pawloski, 2016). The protocol requiring three vaccinations and oxfendazole increases 563 costs to the farmer and likely decreases feasibility (Jayashi et al., 2012; Thomas, 2014). 564 Therefore, the vaccine may be unaffordable for poor communities unless subsidized and 565 supported by provision of infrastructure to deliver the vaccine, including an effective cold chain.

566 Currently, the TSOL18 vaccine is produced commercially at scale by Indian Immunologicals 567 (Thomas, 2015; Geerts, 2016). Although the vaccine has been registered for use since May 2016 568 and can be purchased by any country it is not registered in any West African country probably 569 due to the cost implications associated with the registration process. Therefore, there is no data 
on the vaccine trial in West Africa, even though the authors' personal interview with farmers in

571 North central Nigeria indicates their willingness to purchase the vaccine.

\subsection{Health education}

574

Health education is a significant part of control strategies for T. solium (Garcia et al., 2010; Fleury et al., 2013) and could play a significant role by informing consumers about the risks related to the consumption of infected pork; subsequent refusal to purchase infected meat might assist in a change of management practices, as farmers will acknowledge a clearer economic cost of high-risk practices (Thomas, 2015; Gabriël et al., 2016). Impact could extend throughout the meat supply chain and to health workers and the general population (Thomas, 2015), although like other interventions, education has limitations as a stand-alone approach (Gabriël et al., 2016). A free computer-based health education tool called "The Vicious Worm" was developed to support efforts to control T. solium infections (Johansen et al., 2014), targeting stakeholders across from all professions and sectors and providing information on transmission, diagnosis, risk factors, and prevention and control of the disease (Johansen et al., 2016).

Gap; Recently effectiveness of community-based (EFECAB) educational programme carried out in Burkina Faso showed a reduction in the cumulative incidence of active cysticercosis (adjusted cumulative incidence ratio $0 \cdot 65,95 \%$ Bayesian credible interval $[95 \% \mathrm{CrI}] 0 \cdot 39-1 \cdot 05$ )and a reduction in active cysticercosis prevalence adjusted prevalence proportion ratio $0 \cdot 84 ; 95 \% \mathrm{CrI}$ 0.59-1 18) both from baseline to after randomisation (Carabin et al., 2018). Such studies can be repeated in other countries of West Africa so that health education can be used as a control tool for T. solium cysticercosis in West Africa. 


\subsection{Integrated approach}

Several predictive models have been developed to help design the most effective and feasible intervention strategies for the control of $T$. solium cysticercosis in both pigs and human populations (Braae et al., 2016b; Winskill et al., 2017). The recently developed CystiSim model indicated that combined intervention strategies in both pigs and humans, such as concurrent mass drug administration in humans and vaccination and treatment of pigs, have a high likelihood of success, given a 75\% coverage rate sustained for more than four years (Braae et al., 2016b).

Collaborative networks for $T$. solium control already exist nationally and internationally among researchers, and this effort should be sustained for interaction and transfer of knowledge and findings (Gabriël et al., 2016, WHO, 2016a). A multisectorial and One Health approach across all disciplines including agricultural, food and human health sectors comprising medical, veterinary, environmental, governmental and nongovernmental and social actors is necessary for the control and eradication of cysticercosis and T. solium in both human and pigs (Braae et al., 2016a; Gabriël et al., 2016). Furthermore, it is vital to integrate control of T. solium cysticercosis with other NTDs or within national primary health care systems (Bockarie et al., 2013; Nakagawa et al., 2015) and should be encouraged in West Africa. Efforts to improve scientific understanding and design of optimal control strategies should be cognisant of the fact that the success of any intervention is largely dependent on the level of societal and political acceptance, commitment and engagement of the stakeholders (Gabriël et al., 2016).

\section{Conclusions}

Diverse intervention methods have been recommended and tried in order to control T. solium cysticercosis (Fleury et al., 2013). A multipronged approach consisting of vaccination of pigs 
using TSOL18 vaccine and treatment with oxfendazole along with mass chemotherapy of

617 humans is promising and with praziquantel could eliminate taeniasis. However, the fact remains 618 that long-term and sustainable control, and potentailly elimination, of $T$. solium should 619 preferably include combinations of methods that center on both human and animal hosts. 620 Selected combinations will depend on practicality and economic cost (Mwape et al., 2015). Alas, 621 at present there is inadequate evidence for the best combinations for cost-effective intervention 622 packages in endemic countries (Johansen et al., 2016), thus integration of economics into disease 623 control models might help to rectify this important deficit. Identifying and addressing key 624 obstacles to sustained control efforts, as set out in this review for West Africa, is an essential step 625 in designing rational approaches suited to target regions, and making real progress towards 626 eradication. Diagnostic tools, including neuroimaging facilities, should be strategically situated 627 and made accessible to rural populations in West Africa. This will support efforts to more 628 accurately estimate the burden of disease, highlight the problem to policymakers with competing 629 priorities, and monitor the effectiveness of interventions.

\section{Acknowledgement}

\section{Competing interests}

635 The authors declare no conflict of interests of any kind.

636 Declaration of interest- None

637 Funding:

638

639 
References

653

654

655

656

657

658

659

660

661

662

663

664

665

666

667

668

669

670

671

672

Allan J. C., Velasquez-Tohom M., Torres-Alvarez R., Yurrita P., Garcia-Noval, J. (1996). Field trial of the coproantigen-based diagnosis of Taenia solium taeniasis by Enzyme-Linked Immunosorbent Assay. The Am. J. Trop. Med. Hyg. 54, 352-356.

Assana, E., Craig T. K., Charles G. G., Geerts, S., Dorny, P., 'De Deken, R., Garry, A. A., Zoli P. A., 'Lightowlers M.W. (2010). "Elimination of Taenia solium transmission to pigs in a field trial of the TSOL18 vaccine in Cameroon. Internat. J. Parasitol. 40, 515-519.

Assana, E., Lightowlers, M. W., Zoli, A. P., Geerts, S. (2013). Taenia solium taeniosis/cysticercosis in Africa: risk factors, epidemiology and prospects for control using vaccination. Vet. Parasitol. 195, 14-23.

Atawalna, J., Ewura, S., Mensah. M. (2015). Prevalence and financial losses associated with porcine cysticercosis in the Kumasi metropolis of Ghana. Internat. J. Livestock Res. 5, $21-26$.

Bethony, J., Brooker, S., Albonico, M., Geiger, S. M., Loukas, A., Diemert, D., Hotez, P. J. (2006). Soil-transmitted helminth infections: ascariasis, trichuriasis, and hookworm. The Lancet 367, 1521-1532

Bimi, L., Laar, A. K., Anto, F. (2012). Prevalence and Risk Factors of Taeniasis in the Bunkpurugu-Yunyoo District of Northern Ghana. J. Bacteriol. Parasitol. 3, 129.

Bockarie, M. J., Kelly-Hope, L. A., Rebollo, M., Molyneux, D. H. (2013). Preventive chemotherapy as a strategy for elimination of neglected tropical parasitic diseases: endgame challenges. Philosop. Transac. Roy. Soc B: Biol. Sci. 368, 20120144. 
Braae, U. C., Magnussen, P., Lekule, F., Harrison, W., Johansen, M. V. (2014). Temporal fluctuations in the sero-prevalence of Taenia solium cysticercosis in pigs in Mbeya Region, Tanzania. Parasit. Vectors. 7, 574.

Braae, U. C., Saarnak, C. F., Mukaratirwa, S., Devleesschauwer, B., Magnussen, P., Johansen, M. V. (2015a). Taenia solium taeniosis/cysticercosis and the co-distribution with schistosomiasis in Africa. Parasit. Vectors. 8, 323

Braae, U. C., Harrison, W., Lekule, F., Magnussen, P., Johansen, M. V. (2015b). Feedstuff and poor latrines may put pigs at risk of cysticercosis - A case-control study. Vet. Parasitol. 214, 187-191.

Braae, U. C., Magnussen, P., Ndawi, B., Harrison, W., Lekule, F., Johansen, M. V. (2015c). Effect of repeated mass drug administration with praziquantel and track and treat of taeniosis cases on the prevalence of taeniosis in Taenia solium endemic rural communities of Tanzania. Acta Trop. 165, 246-251

Braae, U. C., Magnussen, P., Harrison, W., Ndawi, B., Lekule, F., Johansen, M. V. (2016a). Effect of national Schistosomiasis control programme on Taenia solium taeniosis and porcine cysticercosis in rural communities of Tanzania. Parasit. Epid. Control. 1, 245251

Braae, U.C., Devleesschauwer, B., Gabriël, S., Dorny, P., Speybroeck, N., Magnussen, P., Torgerson, P., Johansen, M.V. (2016b). CystiSim-an agent-based model for Taenia solium transmission and control. PLoS NTDs. 10, .e0005184.

Carabin, H., Ndimubanzi, P.C., Budke, C.M., Nguyen, H., Qian, Y., Cowan, L.D., Stoner, J.A., Rainwater, E., Dickey, M. (2011). Clinical manifestations associated with neurocysticercosis: a systematic review. PLoS NTDs 5, e1152.

Carabin, H., Millogo, A., Cissé, A., Gabriël, S., Sahlu, I., Dorny, P., Bauer, C., Tarnagda, Z., Cowan, L.D., Ganaba, R. (2015). Prevalence of and factors associated with human cysticercosis in 60 villages in three provinces of Burkina Faso. PLoS NTDs 9, e0004248.

Carabin, H., Millogo, A., Ngowi, H.A., Bauer, C., Dermauw, V., Koné, A.C., Sahlu, I., Salvator, A.L., Preux, P.M., Somé, T. and Tarnagda, Z., 2018. Effectiveness of a community-based educational programme in reducing the cumulative incidence and prevalence of human Taenia solium cysticercosis in Burkina Faso in 2011-14 (EFECAB): a cluster-randomised controlled trial. The Lancet Global Health, 6(4), pp.e411-e425.

Carpio, A., Romo, M. L. (2014). The relationship between neurocysticercosis and epilepsy: an endless debate. Arquivos de Neuro-Psiquiatria. 72, 383-390.

Carpio, A., Fleury, A., Hauser, W. A. (2013). Neurocysticercosis five new things. Neurol. Clin. Pract. 3, 118-125.

Coulibaly, N.D. and K.R. Yameogo, 2000. Prevalence and control of zoonotic diseases: Collaboration between public health workers and veterinarians in Burkina Faso. Acta Trop., 76: 53-57

Del Brutto, O.H. (2013b). Human cysticercosis (Taenia solium). Trop. Parasitol. 3, 100-103.

Devleesschauwer, B., Aryal, A., Tharmalingam, J., Joshi, D.D., Rijal, S., Speybroeck, N., Gabriël, S., Victor, B., Dorny, P. (2013). Complexities in using sentinel pigs to study 
Taenia solium transmission dynamics under field conditions. Vet. Parasitol. 193, 172178.

Donadeu, M., Lightowlers, M. W. (2014). RE: Commercialisation of oxfendazole and TSOL18. Type in Thomas, L.F., 2015. Landscape analysis: control of Taenia solium. http://apps.who.int/iris/bitstream/10665/164359/1/9789241508643_eng.pdf (accessed on 3 June 2017).

Dorny, P., Brandt , J., Geerts, S. (2005). Detection and diagnosis. In: Murrell, K.D. (Ed.), WHO/FAO/OIE Guidelines for the Surveillance, Prevention and Control of Taeniosis/Cysticercosis. OIE, Paris, France, pp: 45-55.

Dumas, M., Grunitzky, E., Deniau, M., Dabis, F., Bouteille, B., Belo, M., Pestre-Alexandre, M., Catanzano, G., Darde, M.L., d'Almeida, M. (1989). Epidemiological study of neurocysticercosis in northern Togo (West Africa). Acta Leidensia. 57, 191-196.

Dumas, M., Grunitzky, K., Belo, M., Dabis, F., Deniau, M., Bouteille, B., Kassankogno, Y., Catanzano, G., PestreAlexandre, M. (1990). Cysticercosis et neurocysticercose: enque^te e'pide'miologique dans le nord du Togo. Bull. Soc. Path. Exot. 83, 263/274.

Edia-Asuke, A. U., Inabo, H. I., Umoh, V. J., Whong, C. M., Asuke, S., Edeh, R. E. (2014). Assessment of sanitary conditions of unregistered pig slaughter slabs and post mortem examination of pigs for Taenia solium metacestodes in Kaduna metropolis, Nigeria. Infect. Dis. Poverty. 3, 45.

Edia-Asuke, A. U., Inabo, H. I., Mukaratirwa, S., Umoh, V. J., Whong, C. M., Asuke, S., Ella, E. E. (2015). Seroprevalence of human cysticercosis and its associated risk factors among humans in areas of Kaduna metropolis, Nigeria. The J. Infect. Develop. Count. 9, 799805.

Ertel, R.L., Braae, U.C., Ngowi, H.A., Johansen, M.V. (2015). Assessment of a computer-based Taenia solium health education tool 'The vicious worm'on knowledge uptake among professionals and their attitudes towards the program. Acta Trop. 165, 240-245.

Evans, D., McFarland, D., Adamani, W., Eigege, A., Miri, E., Schulz, J., Pede, E., Umbugadu, C., Ogbu-Pearse, P. and Richards, F.O. (2011). Cost-effectiveness of triple drug administration (TDA) with praziquantel, ivermectin and albendazole for the prevention of neglected tropical diseases in Nigeria. Ann. Trop. Med. Parasitol. 105, 537-547.

Evans, D.S., King, J.D., Eigege, A., Umaru, J., Adamani, W., Alphonsus, K., Sambo, Y., Miri, E.S., Goshit, D., Ogah, G., Richards, F.O. (2013). Assessing the WHO 50\% prevalence threshold in school-aged children as indication for treatment of urogenital schistosomiasis in adults in central Nigeria. The Am. J. Trop. Med. Hyg. 88, 441-445.

FAO (2012) Secteur porcin Burkina Faso. Revues Nationales del' élevagedela division dela production et de lasanté animals dela FAO.Rome Microbiological Risk Assessment Series 23, FAO/WHO. Accessed November 2015.

Ferrer, E., Gárate, T. (2014). Taeniosis and Cysticercosis. In: Helminth Infections and their Impact on Global Public Health (201-227). Springer Vienna.

Fleury, A., Carrillo-Mezo, R., Flisser, A., Sciutto, E., Corona, T. (2011). Subarachnoid basal neurocysticercosis: a focus on the most severe form of the disease. Expert Rev. Anti. Infect. Ther. 9, 123-133.

Fleury, A., Sciutto, E., De Aluja, A.S., Larralde, C., Agudelo, S., Garcia, G.M., Fandiño, J., Guerra, R., Nunes, C., de Aragão, S.C., Sato, M. (2013). Control of Taenia solium transmission of taeniosis and cysticercosis in endemic countries: the roles of continental 
networks of specialists and of local health authorities. In: Novel Aspects on Cysticercosis and Neurocysticercosis. InTech.

Fleury, A., Sciutto, E., de Aluja, A.S., Carpio, A. (2015). Cysticercosis: A preventable, but embarrassing neglected disease still prevalent in non-developed countries. In. ZoonosesInfections affecting humans and animals. Springer Netherlands 335-354.

Flisser, A. (2013). Epidemiology of Neurocysticercosis in Mexico: From a public health problem to its control. Chapter 9. http://dx.doi.org/10.5772/53839 255-274. InTech.

Gabriël, S., Dorny, P., Mwape, K.E., Trevisan, C., Braae, U.C., Magnussen, P., Thys, S., Bulaya, C., Phiri, I.K., Sikasunge, C.S., Makungu, C. (2016). Control of Taenia solium taeniasis/cysticercosis: The best way forward for sub-Saharan Africa?. Acta Trop. 165, $252-260$

Galan -puchades, M. T. (2016) Taeniasis vs cysticercosis infection routes Asian pacific Journal Tropical Medicine 9(6)619-620

Ganaba, R., Praet, N., Carabin, H., Millogo, A., Tarnagda, Z., Dorny, P., Hounton, S., Sow, A., Nitiéma, P., Cowan, L.D. (2011). Factors associated with the prevalence of circulating antigens to porcine cysticercosis in three villages of Burkina Faso. PLoS NTDs. 5, e927.

Garba, A., Toure ' S., Dembele ' R. , Boisier P., Tohon, Z., Bosque ' -Oliva, E., Koukounari A., Fenwick A. P. (2009), Present and future schistosomiasis control activities with support from the Schistosomiasis Control Initiative in West Africa. Parasitol.136, 1731-1737.

García, H. H., Gonzalez, A. E., Evans, C. A., Gilman, R. H. Cysticercosis Working Group in Peru. (2003). Taenia solium cysticercosis. The Lancet. 362, 547-556.

Garcia, H.H., Gonzalez, A.E., Rodriguez, S., Gonzalvez, G., Llanos-Zavalaga, F., Tsang, V.C. and Gilman, R.H. (2010). Epidemiología y control de la cisticercosis en el Perú [Epidemiology and control of cysticercosis in Peru]. Revista Peruanade Medicina Experimentaly Salud Publica 27, 592-597.

Garcia, H. H., Gonzales, I., Lescano, A. G., Bustos, J. A., Pretell, E. J., Saavedra, H., Nash, T. E. (2014a). Enhanced steroid dosing reduces seizures during antiparasitic treatment for cysticercosis and early after. Epilepsia. 55, 1452-1459.

Garcia, H. H., Nash, T. E., Del Brutto, O. H. (2014b). Clinical symptoms, diagnosis, and treatment of neurocysticercosis. The Lancet Neurol. 13, 1202-1215.

Garcia H H, Castillo Y, Gonzales I, Bustos JA, Saavedra H, Jacob L, Del Brutto OH, Wilkins PP, Gonzalez AE, Gilman RH (2018). Cysticercosis Working Group in Peru. Low sensitivity and frequent cross-reactions in commercially available antibody detection ELISA assays for Taenia solium cysticercosis. Trop Med Int Health. 23(1):101-105.

Geerts, S. (2016) Elimination of Taenia solium cysticercosis through vaccination of pigs: a realistic option?. www.kaowarsom.be/documents/PDF Bulletin/Geerts.pdf (accessed on 2 August 2017).

Gilman, R. H., Gonzalez, A. E., Llanos-Zavalaga, F., Tsang, C. W., Garcia, H. H. (2012). The Cysticercosis Working Group in Peru. Special issue article prevention and control of Taenia solium taeniasis/cysticercosis in Peru. Path. Glob. Hlth. 106, 5.

Gonzalez, A.E., Cama, V., Gilman, R.H., Tsang, V.C., Pilcher, J.B., Chavera, A., Castro, M., Montenegro, T., Verastegui, M., Miranda, E., Bazalar, H. (1990). Prevalence and comparison of serologic assays, necropsy, and tongue examination for the diagnosis of porcine cysticercosis in Peru. The Am. J. Trop. Med.Hyg. 43, 194-199. 
Goussanou, J.S.E., 2010. Evaluation des procédés d'abattage et de la qualité microbiologique des carcasses de porcs locaux des Abattoirs de Cotonou-Porto-Novo et des tueries de Cotonou et de Godomey. Mémoire de fin de formation de master en normes, Contrôle de Qualité et Technologie Alimentaire. UAC. Bénin

Goussanou, J.S., Kpodekon, T.M., Saegerman, C., Azagoun, E., Youssao, A.K., Farougou, S., Praet, N., Gabriël, S., Dorny, P., Korsak, N. (2013). Spatial distribution and risks factors of porcine cysticercosis in southern Benin based meat inspection records. Internat. Res. J. Microbiol. 4, 188-196.

Goussanou, J.S.E., Korsak, N., Saegerman, C., Youssao, A.K.I., Azagoun, E., Farougou, S., Gabriël, S., Dorny, P., Kpodekon, M.T. (2014). Assessment of routine inspection method for diagnostic of porcine cysticercosis in South East Benin by using meat inspection records and Ag-ELISA test. Internat. J. Anim. Vet. Adv. 6, 80-86.

Guezala, M.C., Rodriguez, S., Zamora, H., Garcia, H.H., Gonzalez, A.E., Tembo, A., Allan, J.C., Craig, P.S. (2009). Development of a species-specific coproantigen ELISA for human Taenia solium taeniasis. The Am.J. Trop. Med. Hyg.81, 433-437.

Gweba, M., Faleke, O.O., Junaidu, A.U., Fabiyi, J.P., Fajinmi, A.O. (2010). Some risk factors for Taenia solium cysticercosis in semi intensively raised pigs in Zuru, Nigeria. Vet. Italiana, 46, 57-67. http://www.oie.int/en/international-standard-setting/terrestrial-code/access-online/

Huerta, M., De Aluja, A.S., Fragoso, G., Toledo, A., Villalobos, N., Hernandez, M., Gevorkian, G., Acero, G., Diaz, A., Alvarez, I., Avila, R. (2001). Synthetic peptide vaccine against Taenia solium pig cysticercosis: successful vaccination in a controlled field trial in rural Mexico. Vacc. 20, 262-266.

Humphries, D., Mosites, E., Otchere, J., Twum, W.A., Woo, L., Jones-Sanpei, H., Harrison, L.M., Bungiro, R.D., Benham-Pyle, B., Bimi, L., Edoh, D. (2011). Epidemiology of hookworm infection in Kintampo North Municipality, Ghana: patterns of malaria coinfection, anemia, and albendazole treatment failure. The Am. J. Trop. Med. Hyg. 84, 792-800.

Idika, I. K. , Njoga, U. J., Ezeh, I. O., Iheagwam, C. N., Ezenduka, E.V., Njoga, E., Onah, D. N. (2017) Re-evaluation of porcine cysticercosis in Nsukka area of Enugu State, Nigeria. Asian Pac. J. Trop. Dis. 7, 519-522.

Jayashi, C. M., Arroyo, G., Lightowlers, M. W., Garcı'a, H. H., Rodrı'guez, S., Gonzalez, A. E. (2012). Seroprevalence and risk factors for Taenia solium cysticercosis in rural pigs of northern Peru. PLoS NTDs. 6, e1733.

Johansen, M. V., Trevisan, C., Braae, U. C., Magnussen, P., Ertel, R. L., Mejer, H., Saarnak, C. F. (2014). The Vicious Worm: a computer-based Taenia solium education tool. Trends Parasitol. 30, 372-374.

Johansen, M. V., Trevisan, C., Gabriël, S., Magnussen, P., Braae, U. C. (2016). Are we ready for Taenia solium cysticercosis elimination in sub-Saharan Africa? Parasitol. 144, 59-64.

Komolafe, M.A., Sunmonu, T.A., Afolabi, O.T., Komolafe, E.O., Fabusiwa, F.O., Groce, N., Kett, M., Disu, J.O., Ajiboye, J.K., Olaniyan, S.O. (2012). The social and economic impacts of epilepsy on women in Nigeria. Epilep. Behav. 24, 97-101.

Leslie, J., Garba, A., Oliva, E.B., Barkire, A., Tinni, A.A., Djibo, A., Mounkaila, I., Fenwick, A. (2012). Correction: Schistosomiais and soil-transmitted helminth control in Niger: Cost effectiveness of school based and community distributed mass drug administration. PLoS NTDs. 6, 10-1371. 
Lightowlers, M.W. (2010). Eradication of Taenia solium cysticercosis: a role for vaccination of pigs. Internat. J. Parasitol. 40, 1183-92.

Lightowlers, M. W. (2013). Control of Taenia solium taeniasis/cysticercosis: past practices and new possibilities. Parasitol. 140, 1566-1577.

Lightowlers, M. W., Assana, E., Jayashi, C. M., Gauci, C. G., Donadeu, M. (2015). Sensitivity of partial carcass dissection for assessment of porcine cysticercosis at necropsy. Internat. J. Parasitol. 45, 815-818.

Lightowlers, M. W., Garcia, H. H., Gauci, C. G., Donadeu, M., Abela-Ridder, B. (2016). Monitoring the outcomes of interventions against Taenia solium: options and suggestions. Parasite Immunol. 38, 158-169.

Mayta, H., Talley, A., Gilman, R.H., Jimenez, J., Verastegui, M., Ruiz, M., Garcia, H.H., Gonzalez, A.E. (2000). Differentiating Taenia solium and Taenia saginata infections by simple Hematoxylin-Eosin staining and PCR-Restriction Enzyme Analysis. J. Clin. Microbiol. 38, 133-137.

Millogo, A., Nitiéma, P., Carabin, H., Boncoeur-Martel, M.P., Rajshekhar, V., Tarnagda, Z., Praet, N., Dorny, P., Cowan, L., Ganaba, R., Hounton, S. (2012). Prevalence of neurocysticercosis among people with epilepsy in rural areas of Burkina Faso. Epilepsia. 53, 2194-2202.

Mkupasi, E.M., Ngowi, H.A., Sikasunge, C.S., Leifsson, P.S., Johansen, M.V. (2013a). Efficacy of ivermectin and oxfendazole against Taenia solium cysticercosis and other parasitoses in naturally infected pigs. Acta Trop. 128, 48-53.

Mkupasi, E. M., Sikasunge, C. S., Ngowi, H. A., Johansen, M. V. (2013b). Efficacy and safety of anthelmintics tested against Taenia solium cysticercosis in pigs. PLoS NTDs. 7, e2200.

Mkupasi, E.M., Ngowi, H.A., Sikasunge, C.S., Leifsson, P.S., Johansen, M.V. (2014). Distribution and histopathological changes induced by cysts of Taenia solium in the brain of pigs from Tanzania. J. Helminthol. 89, 559-564.

Molinari, J.L., Soto, R., Tato, P., Rodriguez, D., Retana, A., Sepulveda, J., Palet, A. (1993). Immunization against porcine cysticercosis in an endemic area in Mexico: a field and laboratory study. The Am. J. Trop. Med. Hyg. 49, 502-512.

Mwape, K.E., Blocher, J., Wiefek, J., Schmidt, K., Dorny, P., Praet, N., Chiluba, C., Schmidt, H., Phiri, I.K., Winkler, A.S., Gabriël, S.(2015). Prevalence of neurocysticercosis in people with epilepsy in the Eastern province of Zambia. PLoS NTDs 9, e0003972.

Nakagawa, J., Ehrenberg, J.P., Nealon, J., Fürst, T., Aratchige, P., Gonzales, G., Chanthavisouk, C., Hernandez, L.M., Fengthong, T., Utzinger, J., Steinmann, P. (2015). Towards effective prevention and control of helminth neglected tropical diseases in the Western Pacific Region through multi-disease and multi-sectoral interventions. Acta Trop. 141, .407-418.

Nash, T.E., Garcia, H.H. (2011). Diagnosis and treatment of neurocysticercosis. Nature Rev. Neurol. 7, 584-594.

Ndimubanzi, P.C., Carabin, H., Budke, C.M., Nguyen, H., Qian, Y.J., Rainwater, E., Dickey, M., Reynolds, S., Stoner, J.A. (2010). A systematic review of the frequency of neurocyticercosis with a focus on people with epilepsy. PLoS NTDs 4, e870.

Ngowi, H.A., Mukaratirwa, S., Lekule, F.P., Maingi, N., Waiswa, C., Sikasunge, C., Afonso, S., Sumbu, J., Ramiandrasoa, S., Penrith, M.L., Willingham, A.L. (2013). Agricultural Impact of Porcine Cyisticercosis in Africa: A Review. In Novel Aspects on Cysticercosis and Neurocysticercosis. InTech. 
Nitiéma, P., Carabin, H., Hounton, S., Praet, N., Cowan, L.D., Ganaba, R., Kompaoré, C., Tarnagda, Z., Dorny, P., Millogo, A. (2012). Prevalence case control study of epilepsy in three Burkina Faso villages. Acta Neurolog. Scandinavica. 126, 270-278.

Nkouawa, A., Sako, Y., Li, T., Chen, X., Wandra, T., Swastika, I.K., Nakao, M., Yanagida, T., Nakaya, K., Qiu, D., Ito, A. (2010). Evaluation of a loop-mediated isothermal amplification method using fecal specimens for differential detection of Taenia species from humans. J Clin Microbiol, 48,3350-3352.

Nkouawa, A., Sako, Y., Li, T., Chen, X., Nakao, M., Yanagida, T., Okamoto, M., Giraudoux, P., Raoul, F., Nakaya, K., Xiao, N. (2012). A loop-mediated isothermal amplification method for a differential identification of Taenia tapeworms from human: application to a field survey. Parasitol. Int. 61, 723-725.

Nkrumah, B., Nguah, S.B. (2011). Giardia lamblia: a major parasitic cause of childhood diarrhoea in patients attending a district hospital in Ghana. Parasit. Vectors 4, 163.

Onah, D.N. and S.N. Chiejina, 1995. Taenia solium cysticercosis and human taeniasis in the Nsukka area of Enugu State, Nigeria. Ann. Trop. Med. Parasitol., 89: 399-407.

OIE, 2015. Terrestrial Animal health Code. Chapter 15.3. Infection with Taenia solium.

Osakwe, C., Otte, W. M., Alo, C. (2014). Epilepsy prevalence, potential causes and social beliefs in Ebonyi State and Benue State, Nigeria. Epilep. Res. 108, 316-326.

Pawlowski, Z. (2016). Taeniosis/Neurocysticercosis control as a medical problem-A discussion paper. World J. Neurosci. 6, 2.

Permin, A., L. Yelifari, P. Bloch, N.P. Steenhard and P. Nansen, 1999. Parasites in cross-bred pigs in the upper East region of Ghana. Vet. Parasitol., 87: 63-71.

Phiri, I.K., Dorny, P., Gabriël, S., Willingham, A.L., Sikasunge, C., Siziya, S., Vercruysse, J., (2006). Assessment of routine inspection methods for porcine cysticercosis in Zambian village pigs. J. Helminthol. 80, 69-72.

Pondja, A., Nerves, L., Mlangwa, J., Afonso, S., Fafetine, J., Willingham III, A.L., Thamsborg, S.M., (2012). Use of oxfendazole to controle porcine cysticercosis in a high endemic area of Mozambique. PLoS NTDs. 6, e1651.

Prüss-Ustün, A., Bartram, J., Clasen, T., Colford Jr, J.M., Cumming, O., Curtis, V., Bonjour, S., Dangour, A.D., De France, J., Fewtrell, L., Freeman, M.C. (2014). Burden of disease from inadequate water, sanitation and hygiene in low and middle income settings: a retrospective analysis of data from 145 countries. Trop. Med. Internat. Hlth. 19, 894-905.

Rodrigues, C.L., De Andrade, D.C., Livramento, J.A., Machado, L.R., Abraham, R., Massaroppe, L., Lucato, L.T., Caramelli, P. (2012). Spectrum of cognitive impairment in neurocysticercosis. Differences according to disease phase. Neurol. 78, 861-866.

Ron-Garrido, L., Coral-Almeida, M., Gabriël, S., Benitez-Ortiz, W., Saegerman, C., Dorny, P., Berkvens, D., Abatih, E.N. (2015). Distribution and potential indicators of hospitalized cases of neurocysticercosis and epilepsy in Ecuador from 1996 to 2008. PLoS NTDs 9, e0004236.

Secka, A., Grimm, F., Victor, B., Marcotty, T., De Deken, R., Nyan, O., Herera, O., Van Marck, E., Geerts, S. (2010a). Epilepsy is not caused by cysticercosis in The Gambia. Trop. Med. Internat. Hlth. 15, 476-479. 
Secka, A., Marcotty, T., De Deken, R., Van Marck, E., Geerts, S. (2010b). Porcine cysticercosis and risk factors in The Gambia and Senegal. J. Parasitol. Res. http://dx.doi.org/10.1155/2010/823892.

Secka, A., Grimm, F., Marcotty, T., Geysen, D., Niang, A.M., Ngale, V., Boutche, L., Van Marck, E., Geerts, S. (2011). Old focus of cysticercosis in a Senegalese village revisited after half a century. Acta Trop. 119, 199-202.

Thomas, L. F. (2014). Epidemiology of Taenia solium Cysticercosis in western Kenya. A Thesis submitted for the degree of Doctor of Philosophy University of Edinburgh.

Thomas, L.F., 2015. Landscape analysis: control of Taenia solium. http://apps.who.int/iris/bitstream/10665/164359/1/9789241508643_eng.pdf (accessed on 3 June 2017).

Thys, S., Mwape, K.E., Lefèvre, P., Dorny, P., Marcotty, T., Phiri, A.M., Phiri, I.K., Gabriël, S. (2015). Why latrines are not used: communities' perceptions and practices regarding latrines in a Taenia solium endemic rural area in Eastern Zambia. PLoS NTDs 9, e0003570.

Trevisan, C., Mkupasi, E. M., Ngowi, H. A., Forkman, B., Johansen, M. V. (2016). Severe seizures in pigs naturally infected with Taenia solium in Tanzania. Vet. Parasitol. 220, $67-71$.

Trevisan, C., Devleesschauwer, B., Schmidt, V., Winkler, A. S., Harrison, W., Johansen, M. V. (2017). The societal cost of Taenia solium cysticercosis in Tanzania. Acta Trop. 165, 141-154.

Tsang, V.C., Brand, J.A., Boyer, A.E. (1989). An enzyme-linked immunoelectrotransfer blot assay and glycoprotein antigens for diagnosing human cysticercosis (Taenia solium). J. Infect. Dis. 159, 50-59.

Weka, R.P., Ikeh, E.I. (2009). Seroprevalence of cysticercosis and intestinal parasitism in pigs in Jos metropolis. J. Anim. Vet. Adv. 8, 883-887.

Weka, R. P., Ikeh, E. I., Kamani, J. (2013). Seroprevalence of antibodies (IgG) to Taenia solium among pig rearers and associated risk factors in Jos metropolis, Nigeria. The J. Infect. Dis. Dev. Countries. 7, 067-072.

WHO. Prevention and control of schistosomiasis and soil-transmitted helminthiasis: Report of a WHO Expert Committee. World Health Organization; 2002.

WHO (2010). Working to overcome the global impact of neglected tropical diseases - First WHO report on neglected tropical diseases. Geneva: World Health Organization; 2010.

WHO (2016a). A rationale for investment and action World Health Organization 2016 WHO/HTM/NTD/NZD/2016.

WHO (2016b). Taenia solium taeniasis/cysticercosis diagnostic tools report of a stakeholder meeting Geneva, 17-18 December 2015 WHO/HTM/NTD/NZD/2016.4.

WHO (2015a). Investing to Overcome the Global Impact of Neglected Tropical Diseases: Third WHO Report on Neglected Tropical Diseases 3.

WHO (2015b). Assembling a framework for intensified control of taeniasis and neurocysticercosis caused by Taenia solium: report of an informal consultation, WHO Headquarters, Geneva, 17-18 July 2014.

WHO(2015c). Taenia Solium Taeniasis/cysticercosis diagnostic tools. Report of a stakeholder meeting, Geneva, 17-18 December 2015. 1ra Ed. Génova: WHO UNICEF. 2015. 
Winkler, A.S. (2013). Epilepsy and neurocysticercosis in sub-Saharan Africa. In: Foyaca-Sibat H (ed). Novel aspects on cysticercosis and neurocysticercosis. InTech, Croatia, 2013; 307340. http://www.intechopen.com/books/show/title/novel-aspects-on-cysticercosis-andneurocysticercosis accessed June 2014.

Winkler, A. S., Richter, H. (2015). Landscape analysis: management of neurocysticercosis with an emphasis on low- and middle-income countries. World Health Organization WHO/HTM/NTD/NZD/2015.05.

Winskill, P., Harrison, W. E., French, M. D., Dixon, M. A., Abela-Ridder, B., Basáñez, M. G. (2017). Assessing the impact of intervention strategies against Taenia solium cysticercosis using the EPICYST transmission model. Parasit.Vectors 10, 73.

Yamasaki, H., Allan, J.C., Sato, M.O., Nakao, M., Sako, Y., Nakaya, K., Qiu, D., Mamuti, W., Craig, P.S., Ito, A., (2004). DNA differential diagnosis of taeniasis and cysticercosis by multiplex PCR. J. Clin.Microbiol, 42,548-553.

Zoli, A., Shey-Njila, O., Assana, E., Nguekam, J. P., Dorny, P., Brandt, J., Geerts, S. (2003). Regional status, epidemiology and impact of Taenia solium cysticercosis in Western and Central Africa. Acta Trop. 87, 35-42. 